\title{
Complex genetic predisposition to cancer in an extended HNPCC family with an ancestral hMLH1 mutation
}

\author{
P Hutter, A Couturier, R J Scott, P Alday, C Delozier-Blanchet, F Cachat, S E \\ Antonarakis, F Joris, $M$ Gaudin, L D'Amato, J-M Buerstedde
}

\begin{abstract}
Hereditary non-polyposis colorectal cancer (HNPCC) is characterised by a genetic predisposition to develop colorectal cancer at an early age and, to a lesser degree, cancer of the endometrium, ovaries, urinary tract, and organs of the gastrointestinal tract other than the colon. In the majority of families the disease is linked to mutations in one of the two mismatch repair genes, hMSH 2 or hMLH1. We have found a novel hMLH1 nonsense mutation in a Swiss family with Lynch syndrome, which has been transmitted through at least nine generations. A different tumour spectrum of neoplasms of the skin, soft palate, breast, duodenum, and pancreas was observed in three branches of this family, where there was a virtual absence of colonic tumours. The hMLH1 mutation could not be detected in members of these branches suggesting that at least a second genetic defect predisposing to cancer is segregating in part of the kindred. (F Med Genet 1996;33:636-640)
\end{abstract}

Key words: HNPCC; Lynch; hMLH1 mutation.

Division de Pathologie, Institut Central des Hôpitaux Valaisans, Av Grand-Champsec, 1950 Sion, Switzerland P Hutter

A Couturier

F Cachat

F Joris

M Gaudin

Dept Forschung, Kantonsspital, Basel, Switzerland

R J Scott

Division de Génétique Médicale, CMU, Genève, Switzerland C Delozier-Blanchet $S$ E Antonarakis L D'Amato

Basel Institut für Immunologie, Basel, Switzerland

P Alday

J-M Buerstedde

Correspondence to: Dr Hutter.

Received 5 February 1996 Revised version accepted fo publication 20 March 1996
Hereditary non-polyposis colorectal cancer is probably the commonest cancer predisposition, accounting for approximately $5 \%$ of all cases of colorectal cancers. ${ }^{12}$ This disorder is inherited in an autosomal dominant manner and has a high level of penetrance. The clinical diagnosis relies on the observation of a familial clustering of early onset colorectal cancer. HNPCC kindreds are commonly defined as those in which at least three relatives in two successive generations have a histologically verified diagnosis of colorectal cancer, one of whom should be under 50 years of age. ${ }^{3}$ Although colorectal carcinoma is the predominant form of disease in HNPCC families, up to $40 \%$ of all malignancies in these families are extracolonic cancers of epithelial derived origin. ${ }^{2}$ The second most frequently affected organ is the endometrium and a higher frequency of other cancers has also been reported including the stomach, small intestine, upper renal tract, and ovaries. Additionally, breast cancer, hepatobiliary cancer, pancreatic cancer, skin cancers, and sarcomas have been reported. ${ }^{4}$

Recently, heterozygous germline mutations in any one of the four mismatch repair gene homologues, hMSH2, hMLH1, hPMS1, and hPMS2, have been shown to be linked to HNPCC. ${ }^{5-9}$ Germline mutations in hMSH2 and hMLH1 appear to account for the majority of HNPCC families. ${ }^{10-12}$ The products of these genes are involved in the process of mismatch repair (MMR) by recognising base-base mismatches and unpaired loops, before excising and replacing them with the correct nucleotides. ${ }^{13}$

Evidence suggests that the second wild type copy of the relevant mismatch repair gene is inactivated in HNPCC tumour cells. ${ }^{14} \mathrm{~A}$ remarkable feature of tumour DNA isolated from HNPCC patients is its overall genomic instability, reflecting a mismatch repair deficiency. This phenotype is easily detected as shifts in the electrophoretic mobility of microsatellite DNA sequences containing di- and trinucleotide repeats. ${ }^{15-17}$ Several studies have shown that genomic instability is not restricted to HNPCC, as it is also observed in a substantial proportion of the early onset sporadic forms of colorectal cancer. ${ }^{18}{ }^{19}$

Here we report a mutation analysis in a large family showing an unusual tumour spectrum, with typical manifestations of HNPCC in at least two of its branches but almost exclusively extracolonic tumours in three other branches. In the HNPCC subfamilies of the kindred the causative mutation identified is a $\mathrm{G} \rightarrow \mathrm{A}$ germline transition in the hMLH1 gene, which leads to the truncation of the mature protein. However, this mutation was not detected in patients from the other branches of the family, who still developed several types of cancer, suggesting that they might have inherited at least one different genetic defect strongly predisposing to cancer.

\section{Material and methods}

GENOMIC INSTABILITY IN TUMOURS

Archival paraffin embedded tumour tissues were sectioned and DNA was extracted using two rounds of digestion with proteinase $\mathrm{K}$, followed by three phenol/chloroform extractions at $60^{\circ} \mathrm{C}$. Briefly, tissue sections were deparaffinised with xylene and washed in absolute ethanol. Dried samples were treated with 400 $\mu \mathrm{g} / \mathrm{ml}$ proteinase $\mathrm{K}$ (Boehringer, Mannheim) in $500 \mu \mathrm{l}$ digestion buffer $(10 \mathrm{mmol} / \mathrm{l}$ Tris, $\mathrm{pH}$ $8.0,1 \mathrm{mmol} / 1 \mathrm{EDTA}, 75 \mathrm{mmol} / 1 \mathrm{NaCl}$, and $1 \%$ SDS) at $50^{\circ} \mathrm{C}$ overnight. The pattern of amplification of four microsatellite sequences 
(D6S285, D12S79, D13S225, and GABA55) was compared between DNA from tumour tissue and DNA isolated from peripheral blood cells of the same patient. The DNA was amplified for 30 cycles in $20 \mu \mathrm{l}$ (5-10 pmol of each primer, $50 \mu \mathrm{mol} / 1$ of each $\mathrm{dNTP}$, and $0.1 \mathrm{unit}$ of $T a q$ polymerase). The upstream primer was labelled at its $5^{\prime}$ end using $\left[\gamma^{32} \mathrm{P}\right]$ ATP $(6000$ $\mathrm{Ci} / \mathrm{mmol}$ ) and $\mathrm{T} 4$ polynucleotide kinase. Following PCR, 1-3 $\mu$ l of reaction product were denatured and electrophoresed on denaturing 8\% polyacrylamide gels (Accugel 19:1 from National Diagnostics/ Atlanta). After electrophoresis, the gels were dried and exposed to $x$ ray films for 12-18 hours. The same experimental conditions were used to amplify the markers D3S1277 and D3S1611, linked to the hMLH1 gene.

\section{ANALYSIS OF CDNA}

Total RNA was extracted from $100 \mu$ of fresh blood using Catrimox-14 (Iowa Biotechnology Corp), and cDNA was generated using ran- dom hexamers and reverse transcriptase from Gibco/BRL. A two step PCR using nested primers was used to amplify the hMLH1 transcript in two overlapping fragments. Fragment A contained part of the $5^{\prime}$ UTR and codons 1-394 and fragment B contained codons 325 to the termination codon (756), and part of the 3' UTR.

IN VITRO SYNTHESISED PROTEIN ASSAY (IVSP)

The above products were used as templates for a nested PCR with a $5^{\prime}$ end modified primer that included signals for transcription by $\mathrm{T} 7$ polymerase and a eukaryotic consensus sequence for in vitro coupled transcriptiontranslation (IVSP), in a volume of $25 \mu 1,{ }^{20}$ using $2 \mu \mathrm{l}$ of $\left[{ }^{3} \mathrm{H}\right]$ leucine (Amersham). The products of translation were separated on SDS-12.5\% polyacrylamide gels (Protogel, National Diagnostics/Atlanta), which were then dried and subjected to autoradiography.
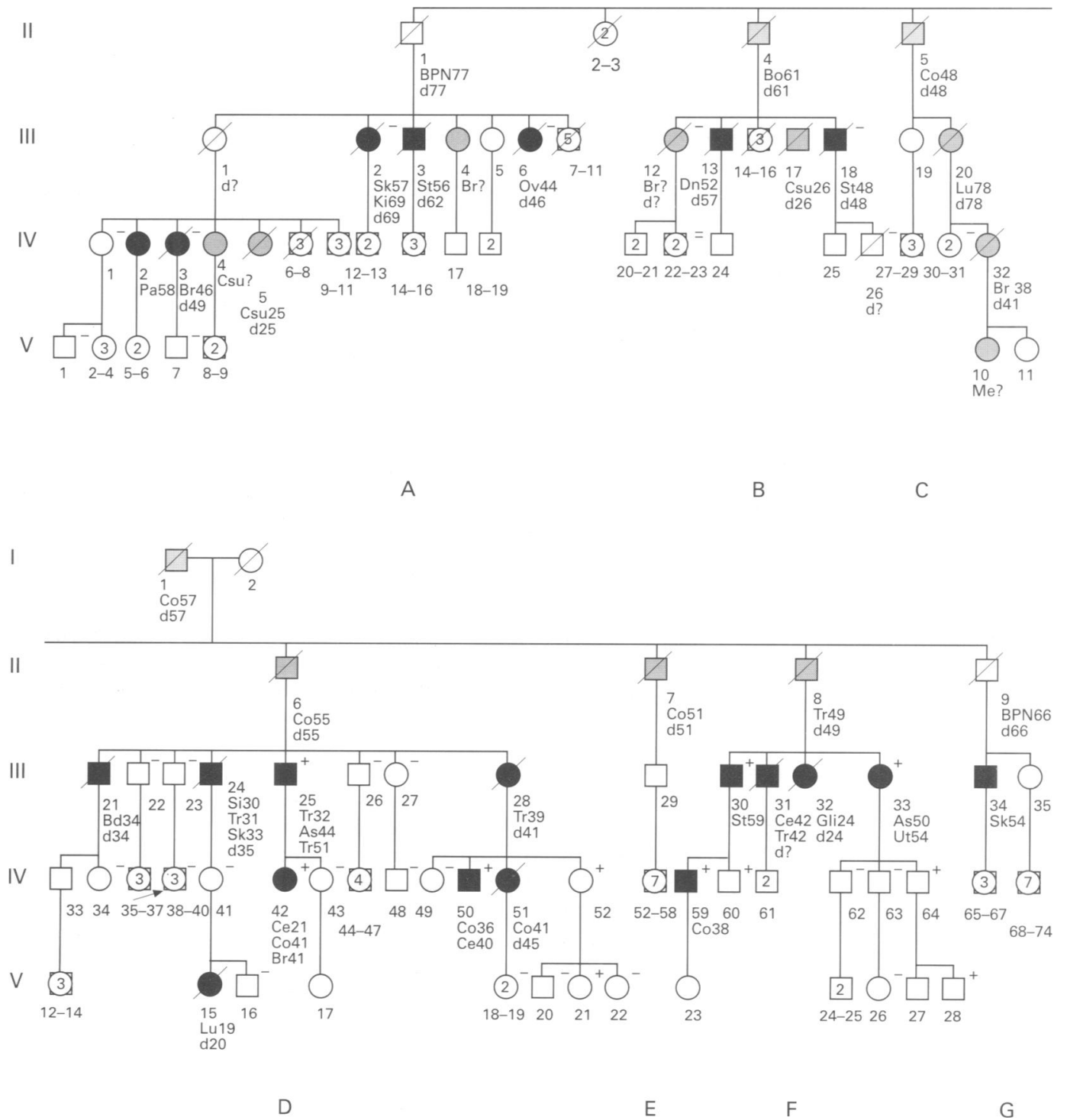

Figure 1 Five generations of the HNPCC kindred under study. Numbers below the symbols are patient identifiers; numbers below the symbols of patients preceded with $d$ indicate age of death. Filled symbols refer to patients whose cancer was verified histologically, shaded symbols to patients whose cancer was determined from family history, and open symbols to patients with no neoplasm detected. Letters represent the site of the tumour as follows: As, ascending colon; Bd, bile duct; Bo, bone; Br, breast; Ce, caecum; Co, colon; Csu, cancer site unknown; Dn, duodenum; Gli, glioblastoma; Ki, kidney; Ov, ovary; Pa, soft palate; Lu, lung; Si, sigmoid; Sk, skin; St, stomach; Tr, transverse colon. Subjects with a plus were identified as carriers of the nonsense mutation at codon 714 of the hMLH1 gene, whereas subjects with a minus are not carriers. 
SEQUENCE ANALYSIS

Sequence analysis was carried out either from products of RT-PCR or from products of PCR from genomic DNA. When necessary these products were purified using a QIAquick PCR purification kit (Qiagen, Germany). Sequencing was performed with SequiTherm Polymerase (Epicentre Technologies, Madison, WI), using primers labelled at their $5^{\prime}$ end with T4 polynucleotide kinase, following the conditions specified by the manufacturer. Alternatively, genomic sequencing was also performed as previously described. ${ }^{21}$ DNA templates from people in whom the mutation reported in this paper was searched for were sequenced in both directions, and results were confirmed by sequencing at least two independent PCR products. Sequences of all primers used for microsatellite amplification, IVSP, and sequencing are available upon request from $\mathrm{PH}$ (e-mail: pierre.hutter@ichv.vsnet.ch).

\section{Results}

The kindred described here comes from an alpine region in southern Switzerland and has previously attracted medical attention..$^{22} \mathrm{New}$ inquiries allowed us to extend the pedigree, as shown in fig 1 , and medical records now document a high incidence of colorectal cancer for the last six generations.

In search for a possible HNPCC mutation, all exons and exon/intron boundaries of the hMSH 2 and hMLH1 genes of patient III.25 were sequenced from genomic DNA. Two polymorphisms were observed, an already reported A to $\mathrm{G}$ transition in hMSH2 at nucleotide +9 of the donor splice site of intron 10 and a novel $G$ to $A$ transition in $\mathrm{hMLH} 1$ at nucleotide +11 of the donor splice site of intron 13. Apart from these polymorphisms a heterozygous $\mathrm{G}$ to $\mathrm{A}$ transition was detected in exon 19 of the hMLH1 gene. This single base substitution AGTGGAC $\rightarrow$ AGTAGAC (fig 2) represents a nonsense mutation that changes codon $714 \mathrm{~W}$ into a termination codon, which predicts a loss of the last 42 amino acids of the mature protein. Using the in vitro synthesised protein assay (IVSP) as a mutation screening test, the same mutation was found independently in the germline of a HNPCC patient from the same locality, but not known at that time to be related to the previous patient. Whereas no abnormal transcripts were detected in either gene, the IVSP assay from hMLH1 showed, in addition to the expected polypeptide, a slightly smaller product (fig 3 ), suggesting the presence of a premature termination codon near the COOH-terminal end of the encoded protein. Sequence analysis of the last two exons of the cDNA and of genomic DNA showed the same point mutation as that found by genomic sequencing of the hMLH1 gene in patient III.25. Further investigation of the family history of the above patient allowed identification of a probable common ancestor nine generations ago.

In order to determine whether we were dealing with two independent events, allele specific markers were used to compare the chromosomal background of the two patients. For this purpose we compared the size of two polymorphic microsatellites, D3S1277 and D3S1611, which had been used for the original linkage analysis of the hMLH1 gene. D3S1277 is located close to this gene and D3S1611 lies within it. $^{823}$ The results indicated that a recombination event had occurred between marker D3S1277 and the above nucleotide 2182 but that the intragenic marker D3S1611 was identical, suggesting that it was inherited from a common ancestor (fig 4). In order to show that the mutation cosegregated with the disease, the entire exon 19 was sequenced from genomic DNA of 41 other members of the kindred (fig 1). The same germline mutation was found in all seven patients who had presented with an early onset cancer and in four

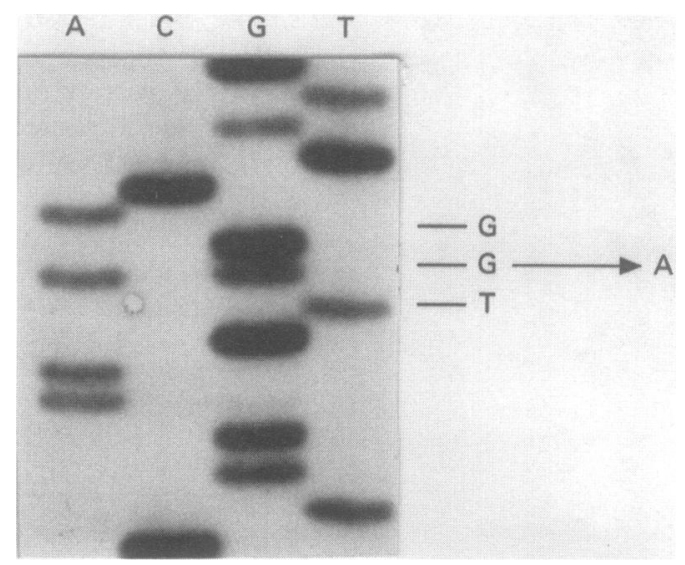

Figure 2 Sequence analysis of a genomic PCR product from patient IV.59, containing exon 19 of the $h M L H 1$ gene. The $G$ to $A$ transition (heterozygous state) indicated by an arrow changes codon $714 W(T G G)$ into a termination codon (TAG).

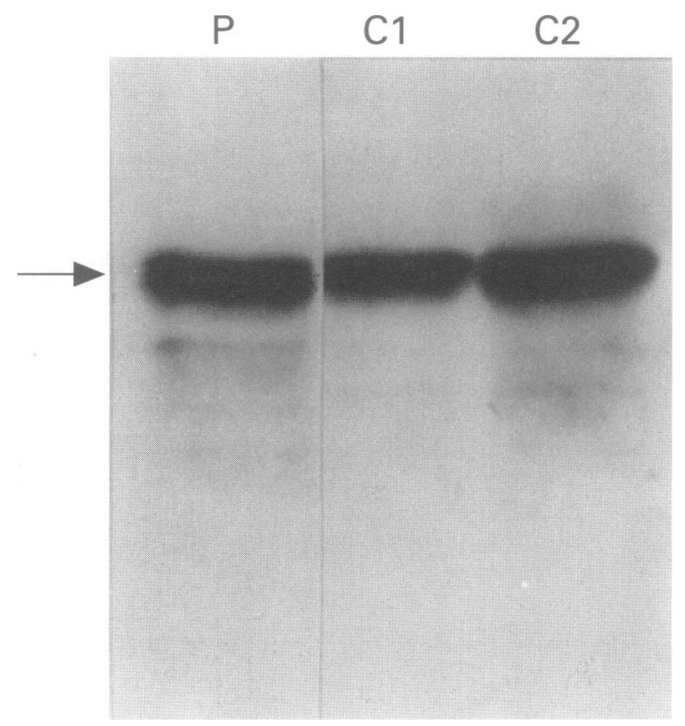

Figure 3 IVSP assays on RT-PCR products of the $h M L H 1$ gene from the patient distantly related to the family shown in fig 1 . In vitro transcription and translation of RT-PCR products were carried out as described in Material and methods and the resultant labelled proteins were separated on an SDS-polyacrylamide gel. The products shown represent the 3' half gene products obtained from the patient $(P)$ and from two non-carriers of the mutation (C1, C2). In addition to a common band, $a$ slightly shorter product (indicated with an arrow) was detected in the patient, corresponding to the expected truncated protein product. In our experiment the predicted size of the normal product synthesised is $46.4 \mathrm{kDa}$, and that of the truncated product is $41.7 \mathrm{kDa}$. 
asymptomatic subjects, of $25,27,46$, and 51 years of age (but see Discussion for the latter patient), whereas 29 healthy subjects did not harbour the mutation. As tumours related to HNPCC are expected to exhibit microsatellite instability (referred to as the $\mathrm{RER}^{+}$phenotype), we investigated DNA extracted from a paraffin embedded primary colorectal tumour in the patient identified by the PTT. Fig 5 shows that in this patient three out of four microsatellite sequences investigated were found to be unstable.

As shown in fig 1, a strikingly high incidence of various cancers is observed among members of branches $A, B$, and $C$ of the pedigree, without typical manifestations of the HNPCC syndrome, apart from patient II.5. Since no living patients from either branches A or B were available, we analysed genomic DNA from paraffin embedded material from patients III.6, III.18, and IV.3, who had developed early onset ovary, stomach, and breast cancer, respectively. Indeed we were able to detect the mutation at codon 714 of the hMLHl gene from genomic DNA extracted from paraffin embedded tissue of the patient whose mutation was identified by the PTT. In addition, exon 19 was sequenced from subjects III.12, IV.1, IV.22, IV.23, IV.26, IV.31, V.1, and V.7, even though none of the latter manifested any hallmarks of HNPCC. Importantly, the hMLH1 mutation reported above was not found in the examined members of these three

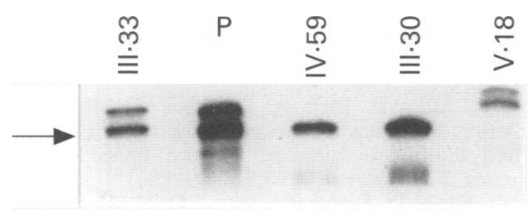

A

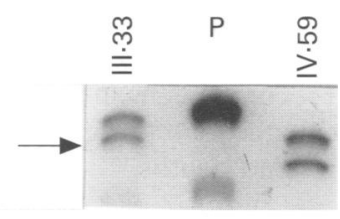

B
Figure 4 Genotype analysis from $P C R$ products generated by amplification of polymorphic markers D3S1611 (A) and D3S1277 (B), situated within and very near the $h M L H 1$ gene, respectivaly. Numbers refer to people in fig 1 and $P$ refers to the patient distantly related to the family shown in fig 1, whose mutation was detected by the PTT. The arrows indicate the common alleles shared by mutation carriers for the two markers, one of which is not shared (in B) by patient P for marker D3S1277. This allele was also found in four other mutation carriers in the family (data not shown).
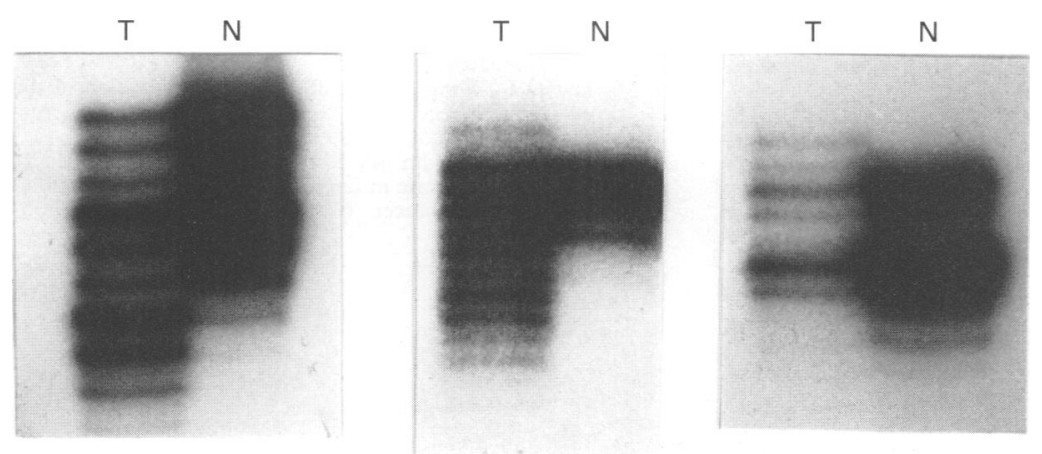

Figure 5 Detection of genetic instability of paired normal $(N)$ and colorectal tumour $(T)$ DNA from the patient whose mutation was identified by the PTT. Dinucleotide repeat patterns are shown for three loci, D6S285, D12S79, and GABA55, respectively. At each locus, tumour DNA exhibits an abnormal pattern, indicating a somatic gain of alleles as a result of microsatellite expansion or deletion. branches, suggesting that the mutation did not spread to branches A, B, and probably C of the kindred under study.

\section{Discussion}

The identification of the molecular defect underlying the predisposition to HNPCC in this family allowed the identification of additional branches of the kindred by virtue of the presence of the identified mutation in patients living in the same region, and thus to extend the pedigree further. On the basis of death certificates and the identification of probable carriers segregating with the disease in this kindred, the MMR mutation could be traced back at least nine generations, to the early 18 th century.

Our data have established that the identified mutation in the hMLH1 gene is responsible for the predisposition to HNPCC in several members of this family, but that some cancer patients who are not carriers probably harbour at least one other genetic defect predisposing to a less restricted range of cancers. The mutation identified in the hMLH1 gene introduces a premature stop codon which is expected to lead to a protein lacking the last 42 amino acids of its mature form, 19 of which (45.2\%) are conserved between yeast and man. ${ }^{78}$ In fact, the last 13 amino acids of yeast and human proteins are identical. We have confirmed segregation of the mutation with the disease in seven patients, whereas people without the mutation are all asymptomatic with respect to Lynch syndrome. The penetrance of the mutation appears to be high, since most ascertained carriers developed a cancer early in life, except III. 30 who presented symptoms of a gastric cancer at the age of 59. Mutation carrier IV.52 is cancer free at the age of 51 but has been regularly monitored, with ablation of several intestinal polyps. Although the same mutation has not been observed in other HNPCC families, mutations affecting the same region of the $\mathrm{COOH}$-terminal end of the hMLH1 protein have been reported in three HNPCC families. The first mutation is a $4 \mathrm{nt}$ deletion beginning at the first position of codon 727, which produces a frameshift with a new stop codon 166 nucleotides downstream, within the 3' untranslated region. ${ }^{8}$ The second mutation, found by the same authors, is a $4 \mathrm{nt}$ insertion between codons 755 and 756, and the third mutation is an $A$ to $T$ transversion at +1 of the IVS18 splice acceptor site. ${ }^{21}$ Although HNPCC has been known for some time to be frequently associated with an increased risk of cancer of the uterus, ovary, stomach, and even small intestine, skin, and larynx ${ }^{2}$ our data indicated that the clinical manifestations observed in branches $A, B$, and $C$ are unlikely to be associated with the mutation identified in the hMLH1 gene.

Therefore, the presence of at least two mutations predisposing to cancer in this kindred illustrates the potential difficulties that can be encountered when evaluating cancer risk among non-carriers of a first mutation incriminated in cancer predisposition in a small HNPCC family. Indeed, the additional germ- 
line mutation(s) which has to be postulated to account for the high incidence of cancers in branches $\mathrm{A}, \mathrm{B}$, and $\mathrm{C}$ may also have been inherited by some patients from the branches of the kindred with HNPCC. This would make the prediction of the cancer risk for noncarriers of the hMLH1 mutation in the whole kindred difficult, as long as additional mutations are not identified. As recently suggested by other workers, ${ }^{24}$ one could speculate that the hMLH1 mutation which we identified acts as an allele whose dominant negative or haploinsufficient effect might lead to a reduced level of MMR in non-neoplastic cells, thus favouring mutations in other genes involved in the cancers observed in branches $\mathrm{A}, \mathrm{B}$, and $\mathrm{C}$. This would be consistent with the observation of an apparent phenomenon of anticipation in this family as well as with the predominance of male cancers. ${ }^{22}$ Therefore, screening of more patients for germline mutations in TP53 and in all known MMR genes, starting from the hPMS2 gene whose product is known to form a heterodimeric complex with the protein encoded by $\mathrm{hMLH} 1,{ }^{13}{ }^{25}{ }^{26}$ will be performed. In addition, alterations in other genes, such as the possible target gene encoding receptor II of the TGF- $\beta,{ }^{27}$ will be searched for in some of the primary tumours. The characterisation of the hMLH1 mutation which very strongly predisposes to HNPCC in branches $D$ and $F$ allows presymptomatic diagnosis in the youngest and future members of the family. In addition to the advantage of sparing the anxiety and discomfort associated with colonoscopies for non-carriers of the mutation, enhanced surveillance of carriers has recently been shown both to decrease the incidence of colorectal cancer and to prevent its related deaths. ${ }^{28}$

This work was supported by grants from the following institutions to P Hutter: Recherche Suisse Contre le Cancer, Ligue Genevoise Contre le Cancer, Fondation E Boninchi, and Fondation pour la Lutte Contre le Cancer. We are grateful to Drs R Berclaz and J-M Céréda for providing patients. We thank A Schönbörner and S Fournier for technical help. The Basel Roche \& Co Ltd.

1 Aaltonen LA, Sankila R, Mecklin JP, et al. A novel approach to estimate the proportion of hereditary non-polyposis colorectal cancer of total colorectal cancer burden.Cancer Detect Prev 1994;18:57-63.

2 Lynch HT, Smyrk TC, Watson P, et al. Genetics, natura history, tumor spectrum and pathology of hereditary nonpolyposis colorectal cancer: an updated review. Gastroenterology 1993;104:1535-49.

3 Vasen HF, Mecklin JP, Khan PM, Lynch HT. The International Collaborative Group on Hereditary NonInternational Collaborative Group on Hereditary NonRectum 1991;34:424-5.

4 Rectum 1991;34:424-5. hereditary non-polyposis colorectal cancer(HNPCC) and in families with "suspected HNPCC". A population-based tudy in Northern Italy. Int $\mathcal{A}$ Cancer 1993;54:371-7.

5 Fishel R, Lescoe MK, Rao MR, et al. The human mutator gene homolog hMSH2 and its association with hereditary non-polyposis colon cancer. Cell 1993;75:1027-38.

6 Leach FS, Nicolaides NC, Papadopoulos N, et al. Mutations of a mutS homolog in hereditary nonpolyposis colorectal cancer. Cell 1993;75:1215-25.

7 Bronner CE, Baker SM, Morrison PT, et al. Mutation in the DNA mismatch repair gene homologue hMLH1 is associated with hereditary non-polyposis colon cancer. Nature 1994;368:258-61.

8 Papadopoulos N, Nicolaides NC, Wei YF, et al. Mutation of a mutL homolog in hereditary colon cancer. Science 1994; 263:1625-9.

9 Nicolaides NC, Papadopoulos N, Liu B, et al. Mutations of two PMS homologues in hereditary nonpolyposis colon cancer. Nature 1994;371:75-80.

10 Liu B, Parsons RE, Hamilton SR, et al. hMSH2 mutations in hereditary non-polyposis colorectal cancer kindreds. Cancer Res 1994;54:4590-4

11 Han HJ, Maruyama M, Baba S, Park JG, Nakamura Y. Genomic structure of human mismatch repair gene, $\mathrm{hMLH1}$, and its mutation analysis in patients with hereditary non-polyposis colorectal cancer (HNPCC). Hum Mol Genet 1995;4:237-42.

12 Wijnen J, Vasen $\mathrm{H}$, Khan PM, et al. Seven new mutations in hMSH2, an HNPCC gene, identified by denaturing hMSH2, an HNPCC gene, identified by denaturing gradient-ge

13 Modrich P. Mismatch repair, genetic stability and cancer. Science 1994;266:1959-60.

14 Parsons R, Li GM, Longley M, et al. Hypermutability and mismatch repair deficiency in $\mathrm{RER}^{+}$tumor cells. Cell 1993;75:1227-36

15 Ionov Y, Peinado MA, Malkhosyan S, Shibata D, Perucho M. Ubiquitous somatic mutations in simple repeated sequences reveal a new mechanism for colonic carcinogenesis. Nature 1993;363:558-61.

16 Strand M, Prolla TA, Liskay RM, Petes TD. Destabilization of tracts of simple repetitive DNA in yeast by mutations of tracts of simple repetitive DNA in yeast by mutation

17 Thibodeau SN, Bren G, Schaid D. Microsatellite instability in cancer of the proximal colon. Science 1993;260:816-19.

18 Liu B, Farrington SM, Petersen GM, et al. Genetic instability occurs in the majority of young patients with colorectal cancer. Nature Med 1995;4:348-52.

19 Liu B, Nicolaides NC, Markowitz S, et al. Mismatch repair gene defects in sporadic colorectal cancers with microsatellite instability. Nature Genet 1995;9:48-55.

20 Roest PAM, Roberts RG, Sugino S, van Ommen G-JB, den Dunnen JT. Protein truncation test (PTT) for rapid detection of translation-terminating mutations. Hum Mol Genet 1993;2:1719-21.

21 Buerstedde JM, Alday P, Torhorst J, Weber W, Müller H, Scott R. Detection of new mutations in six out of 10 Swiss Scott R. Detection of new mutations in six out of 10 Swiss families by genomic sequencing of the hMS

22 Dubosson JD, Klein D, Pettavel J, Rey CD. Syndrome du cancer familial à travers 4 générations. Schweiz Med Wochenschr 1977;107:875-81.

23 Nyström-Lahti M, Sistonen P, Mecklin JP, et al. Close linkage to chromosome $3 p$ and conservation of ancestral founding haplotype in hereditary nonpolyposis colorectal cancer families. Proc Natl Acad Sci USA 1994;91:6054-8.

24 Parsons $\mathrm{R}$, Li GM, Longley $M$, et al. Mismatch repair deficiency in phenotypically normal human cells. Science 1995;268:738-40.

25 Prolla TA, Pang Q, Alani E, Kolodner RD, Liskay RM MLH1, PMS1, and MSH2 interactions during the initiaMLH1, PMS1, and MSH2 interactions during the initiation of DNA

$26 \mathrm{Li} \mathrm{GM}$, Modrich P. Restoration of mismatch repair to nuclear extracts of $\mathrm{H} 6$ colorectal tumor cells by a heterodimer of human MutL homologs. Proc Natl Acad Sci USA 1995;92:1950-4.

27 Markowitz S, Wang J, Myeroff L, et al. Inactivation of the type II TGF-b receptor in colon cancer cells with microsatellite instability. Science 1995;268:1336-8.

28 Järvinen HJ, Mecklin JP, Sistonen P. Screening reduces colorectal cancer rate in families with hereditary nonpolyposis colorectal cancer. Gastroenterology 1995;108:140511 . 